\title{
MEMÓRIA E ESCRITA NO ROMANCE DE JÚLIA ALVAREZ HOW THE GARCÍA GIRLS LOST THEIR ACCENTS
}

\author{
Juraci Andrade de Oliveira Leão ${ }^{*}$
}

\begin{abstract}
Resumo:O objetivo desse trabalho é discutir como que Yolanda, uma personagem do romance de Julia Alvarez How the García Girls Lost Their Accents tenta reconstruir sua identidade através de suas memórias e como que o processo da escrita contribui nessa reconstrução. Em seu retorno ao passado, a personagem recupera momentos que poderão explicar seu sentimento de estar sempre incompleta. Se por um lado essa busca se torna importante no sentido de ajudá-la a externalizar suas carências e múltiplos eus, por outro lado é a escrita que contribuirá para o processo de reconstrução do sujeito.
\end{abstract}

Palavras-chave: memórias, identidade, escrita e sujeito.

Naquela época, tentei, em vão, escrever outras linhas. Mas as palavras parecem

esperar a morte $e \quad o$ esquecimento: permanecem soterradas, petrificadas, em estado latente, para depois, em lenta combustão, acenderem em nós o desejo de contar passagens que o tempo dissipou. E o tempo, que nos faz esquecer, também é cúmplice delas. Só o tempo transforma nossos sentimentos em palavras mais verdadeiras...

(Milton Hatoum, Dois Irmãos)

Os nexos entre memória e escrita têm sido investigados como um importante recurso de reconstituição dos sujeitos em contextos em que estes se acham fragmentados ou deslocados no tempo e no espaço, como por exemplo, no caso da literatura de imigrantes. É o caso da obra de Julia Alvarez, escritora dominicana radicada nos Estados Unidos. A partir da discussão de conceitos desenvolvidos por alguns escritores como Homi Bhabha, Julia Kristeva, Silviano Santiago e Wander Melo Miranda, pretendo analisar a relação entre memória e escrita tendo como pano de fundo a personagem Yolanda, protagonista da obra dessa autora intitulada How the García Girls Lost Their Accents.

\footnotetext{
* Mestre em Literaturas de Expressão em Língua Inglesa e doutoranda em Literatura Comparada pela UFMG
} 


\section{Memória e escrita: estabelecendo conexões a partir da obra de Julia Alvarez}

Memória e escrita caminham juntas na narrativa de Julia Alvarez How the García Girls Lost Their Accents. A emergência de diferentes vozes revela um passado reprimido e expõe um conjunto de acontecimentos desordenados, os quais se tornam compreensíveis e significantes no decorrer da estória. As recordações surgem a partir de um passado nebuloso e são inseridas no presente da narrativa, revelando a história dos personagens. Em uma via de mão dupla, enquanto a escrita se movimenta em direção ao presente, a memória toma a direção oposta.

Para Wander Melo Miranda, "lembrar é descobrir, desconstruir, desterritorializar - atividade produtiva que tece com as idéias e imagens do presente a experiência do passado" (1992:120). O passado se torna o instrumento de referência e lugar de reorientação para o presente. A escrita cumpre um papel importante nesse processo, pois o ato de registrar as memórias possibilita esse espaço para a reflexão. Assim como um espelho que ao retratar o real revela uma imagem invertida, o texto também faz emergir uma imagem que pode ser igualmente significativa, pois propicia uma releitura do passado. Entre fragmentos desconexos, o escritor tem a função de organizar o texto para torná-lo compreensível. Desse modo, continua o autor:

o resultado são idas-e-vindas, interrupções e retomadas da matéria narrada, as anexações parciais e nunca integrais dos conteúdos da experiência, as reminiscências arredias e articulações definitivas" (1992:121).

No processo de revisita ao passado, o escritor poderá resgatar imagens, estabelecer sua ordem, tendo a chance de obter uma nova visão sobre essas imagens.

Se a memória e a escrita são importantes no retorno ao passado, igualmente importante será o lugar de enunciação, principalmente se considerarmos que o trabalho do escritor poderá ser permeado pela cultura daquele local. No caso de Júlia Alvarez, escritora latino-americana radicada nos Estados Unidos, esse aspecto nos parece ainda mais relevante nessa discussão, uma vez que a escritora traz consigo traços de ambas as culturas. Nascida na República Dominicana, ainda criança Julia Alvarez vive o trauma de ser forçada a abandonar seu país de origem junto com sua família para escapar da repressão política conduzida pelo ditador Trujillo. Nos Estados Unidos, depois de enfrentar as barreiras da língua e da cultura, a escritora se dá conta de sua condição de "outsider". Edward Said, discutindo o exílio, afirma:

it not only meant years of aimless wandering away from family and familiar places, but also meant being a sort of permanent outcast, someone who never felt at home, and was always at odds with environment, inconsolable about the past, bitter about the present and the future. (1994:35). ${ }^{1}$

Esse sentimento de não pertencer ao lugar e a busca por suas referências no passado parecem ser o fio condutor da narrativa de Alvarez. Se por um lado, essa condição de desterritorializado, sem fixidez fragiliza o sujeito, por outro é por não estar preso a nenhum lugar que o escritor se fortalece e se afirma. Para Júlia Kristeva:

\footnotetext{
1 "Não significou apenas anos de um incerto distanciamento da família e dos lugares conhecidos, mas também significou um tipo de exílio permanente, alguém que nunca se sentia em casa, e era sempre estranho ao ambiente, inconsolável em relação ao passado e angustiado em relação ao presente e futuro." (minha tradução)
} 
$\mathrm{O}$ estrangeiro fortifica-se com esse intervalo que o separa dos outros de si mesmo, dando-lhe um sentimento altivo, não por estar de posse da verdade, mas por relativizar a si próprio e aos demais, quando estes encontram-se nas garras da rotina da monovalência. (1994:14).

A condição diferenciada dos demais estabelece uma comparação de si próprio com os outros e o coloca diante de si mesmo. A segurança familiar de outrora é substituída pela ansiedade em relação ao novo, gerando uma instabilidade constante. Segundo Piglia, "La identidad se construye fuera de ahi, em outro espacio: no familiar, desconocido, extranjero, artificial, extralocal" (1991:65). Será portanto, através do estranhamento em relação aos outros e do distanciamento de ambas culturas que o escritor terá condições de visualizar a si mesmo e se constituir enquanto sujeito. Segundo o autor:

Não pertencer a nenhum lugar, nenhum tempo, nenhum amor. A origem perdida, o enraizamento impossível, a memória imergente, o presente em suspenso. O espaço do estrangeiro é um trem sem marcha, um avião em pleno ar, a própria transição que exclui a parada (Kristeva, 1994:15).

É por não se sentir preso a nenhum lugar que o escritor transita entre as duas culturas sem necessariamente se ancorar em alguma delas. Essa transitoriedade e ausência de suporte fazem com que o sujeito procure repouso em si mesmo.

Também é verdade que a aquisição de duas culturas desloca o sujeito e faz com que o sentimento de não pertencer a nenhuma delas o deixe às margens de ambas. Ou seja, o sujeito se torna um estranho tanto no país de origem quanto no país exilado. Se por um lado essa condição o fortifica, por outro lado, esse não pertencer a lugar algum revela também sua solidão. A angústia causada por essa dupla marginalização fará com que o sujeito busque terreno na escrita. Edward Said ao citar Adorno, afirma: "For a man who no longer has a homeland, writing becomes a place to live" (1994:43). ${ }^{2}$ Ao tomar consciência da impossibilidade de assumir uma única cultura e o esforço para achar uma acomodação, faz com que o sujeito encontre conforto na escrita. A escrita, segundo Foucault, "atenua os perigos da solidão" (1992:130). Seu exercício preenche o tempo e o vazio provocado pelo isolamento do sujeito.

\section{Yolanda: in-between}

À luz dessas reflexões podemos analisar a forma como Yolanda, a principal personagem do romance How the García Girls Lost Their Accents, de Julia Alvarez, busca reconstruir sua identidade através da memória e como o processo da escrita contribui nessa reconstrução. O desenvolvimento de sua identidade irá ser feito através de lembranças fragmentadas e de sua externalização através da escrita. Nesse sentido, a forma como a narrativa foi organizada, partindo do fim para o começo na ordem temporal, já indica ao leitor a importância da escrita na reconstituição da identidade da personagem. Essa inversão na ordem cronológica também explica o movimento da memória ao retomar o passado na reorientação do presente.

Semelhante a um diário autobiográfico, esse romance possui três partes datadas e subdividas em quinze capítulos interdependentes. O Capítulo 1 é o mais recente, ou seja, narra o presente da personagem, sendo que os outros seguem uma ordem

\footnotetext{
2 "Para um homem que não mais possui um lar, a escrita torna-se um lugar para se viver." (minha tradução)
} 
cronológica retrospectiva. Os únicos capítulos que se ligam são o primeiro e o último os quais irão dar à estória seu fechamento. $\mathrm{Na}$ introdução do romance existe ainda uma árvore genealógica com todas as referências da família García desde seus ancestrais, o que de uma certa forma já funciona como um direcionamento para o leitor de quem-équem nessa estória. A narrativa relata o cotidiano de uma família latino-americana e suas dificuldades quando se vê obrigada a conviver com uma outra cultura. Essa família é composta pelo pai, a mãe e suas quatro filhas. Entre elas, Yolanda é a que parece se sentir mais incomodada pela sua condição de estrangeira em ambos os paises, nos Estados Unidos e em sua terra natal, a República Dominicana. Muito embora as outras filhas também sofram na busca de se adaptarem à nova cultura, Yolanda é a que se demonstra mais afligida por essa mudança. Isso se revela mais claramente na passagem em que a personagem retorna ao país de origem em busca de suas raízes familiares. Figura ambígua que irá de todas as formas procurar sua estabilidade emocional no curso da narrativa.

Sua necessidade de retornar ao passado demonstra seu esforço em se localizar em um lugar permanente. Ironicamente esse retorno ao passado em busca de uma estabilidade já indica um deslocamento, ou seja, uma certa instabilidade. Essa instabilidade emocional parece estar ligada a sua condição "intervalar" causada pela aquisição das duas culturas. Yolanda deixa transparecer sua ambigüidade nos mais diversos segmentos de sua vida. Ela busca sua referência na literatura, mas tem dificuldade em se centrar e se afirmar como escritora. Em seus relacionamentos afetivos, Yolanda demonstra inquietude e insegurança diante de seus parceiros, o que faz com esses relacionamentos não sejam duradouros.

\section{Yolanda e John: múltiplos eus}

Durante o tempo em que esteve casada com John, Yolanda era consciente da impossibilidade de se entenderem, "But Yolanda was afraid. Once they got started on words, there was no telling what they could say" (1992:70). ${ }^{3}$ Ela estava certa da incapacidade deles de se comunicarem tanto pela diferença cultural, quanto pela suas diferentes visões de mundo. Uma outra consequiência deste relacionamento é que John a fazia se sentir confusa pelas várias formas que ele usava para se dirigir a ela: Yo, Joe, Yoyo, Violet and Squirrel. Essa redução de seu nome Yo, mudança para outro nome em inglês Joe, associação ao brinquedo Yoyo ou à cor Violet (violeta) ou ainda ao animal Squirrel (esquilo) já indicam a atitude dele em caracterizá-la como inferior.

Assim como seu passado estava dividido em momentos desconexos, Yolanda também era dividida em múltiplos eus. Na companhia de seu marido, ela se sentia fragmentada: "No, no, no, she didn't want to divide herself anymore, three persons in one Yo" (1992:78). ${ }^{4}$ John não somente reforçou sua identidade dupla, mas também fez com que ela acreditasse em sua insanidade: "What you need is a goddam shrink!" (1992:73). ${ }^{5}$ Em seus jogos com rimas, ela ainda tentava manter sua unidade ao denominar a si própria como "sky" (céu) que combinaria com "I" (eu). Com isso, resguardava sua individualidade e sanidade: "that was no reason to make her feel crazy for being her own person" (1992:73). "Mais ainda, sendo "sky" ou "cielo in Spanish"

\footnotetext{
3 "Mas Yolanda estava com medo. Uma vez introduzidas as palavras, não haveria limites para o que poderiam dizer." (minha tradução)

4 "Não, não, não, ela não queria mais se dividir, três pessoas em uma única Yo." (minha tradução)

5 "O que você precisa é de um maldito terapeuta!" (minha tradução)

6 "Não havia razão para fazê-la sentir-se louca por ser ela mesma." (minha tradução)
} 
Yolanda era capaz de contemplar os dois mundos, a República Dominicana e os Estados Unidos, ao invés de ser somente mais um "squirrel" no território de John.

John era um pragmático que acreditava somente no mundo real, enquanto Yolanda estava intimamente ligada ao mundo da arte. Diferentemente dele, ela estava sempre tentando achar um significado para as coisas. Talvez essa atitude possa explicar sua constante necessidade de traduzir o mundo através do uso do dicionário:

Back in those days I had what one teacher called 'a vivacious personality'. I had to look up the word in the dictionary and was relieved to find out it didn't mean I had problems. English was then still a party favor for me - crack open the dictionary, find out if I'd just been insulted, praised, admonished, criticized (1992:87). ${ }^{7}$

Para Yolanda a resposta estava sempre na literatura. Esta foi uma das razões que fez com que ela tomasse a decisão de se tornar uma poetisa. Sua relação com a poesia pode ser vista como uma tentativa de encontrar um terreno para si própria, ou ainda a poesia funcionaria como um refúgio onde ela pudesse obter sua subjetividade.

\section{A busca da unidade do eu pela poesia}

Yolanda irá encontrar na escrita seu próprio lugar. Na Visão de Catherine Belsey, o tema central da poesia dos românticos está ligado a subjetividade do autor:

The 'I' of (their) poems is a kind of super-subject, experiencing life at a higher level of intensity than ordinary people and absorbed in a world of selfhood which the phenomenal world, perceived as external and antithetical, either nourishes or constrains (1996:599). ${ }^{8}$

Tal afirmação nos parece adequar perfeitamente à perspectiva de Yolanda, principalmente por ela estar sempre tentando manter fidelidade ao que acreditava. Para essa personagem, a razão estava sempre no campo das idéias e palavras, diferentemente de John que estava preso aos fatos do mundo real. Nesse sentido, a literatura irá ser seu suporte.

No momento em que se encontra no limiar da loucura e da sanidade, Yolanda retoma seu passado:

She recognizes the unmistakable signs of a flashback: a woman at a window, a woman with a past, with memory and desire and wreckage in her heart. She will let herself have them today. She can't help herself anyway (1992:69). ${ }^{9}$

Yolanda percebe que nesse retorno ela tem a oportunidade de compreender seu presente. Para Miranda:

\footnotetext{
7 'De volta àqueles dias, eu tinha aquilo que um professor chamou 'personalidade ativa'. Tendo que procurar a palavra no dicionário, senti-me aliviada ao perceber que aquilo não significava problemas. $\mathrm{O}$ inglês era-me ainda, de uma certa forma, uma conveniência - aberto o dicionário, saberia se tinha sido insultada, elogiada, repreendida, criticada." (minha tradução)

8 "O 'eu' de seus poemas era como um super-sujeito, experimentando a vida em um nível mais elevado que as pessoas comuns e absorvido em um mundo particular que o mundo objetivo, percebido como externo e antitético, tanto alimenta quanto restringe." (minha tradução)

9 "Ela reconhece os inconfundíveis sinais de um flasback: uma mulher na janela, uma mulher com um passado, com memória, desejo e naufrágio em seu coração. Ela se permitirá tê-los hoje. De qualquer maneira, ela não pode evitar." (minha tradução)
} 
Enquanto maneira de recolher as leituras feitas e de se recolher nelas, representam um exercício racional que se opõe à estultice que a leitura infinita arrisca favorecer; e, em conseqüência, contribuem para o apaziguamento da agitação e da inquietação do espírito através da posse de um passado resguardado, no qual a situação presente do indivíduo é impressa pela meditação (1992:28).

É portanto, nesse momento consigo mesma que Yolanda pode clarear sua confusão mental e encontrar sua estabilidade emocional. $\mathrm{O}$ fato de reconstruir o passado através da escrita faz também com que ela consiga ao mesmo tempo estabelecer a lógica desse passado, ou seja, suas recordações se tornarão inteligíveis através da escrita.

Sua dificuldade em lidar com o mundo (world) estava relacionada à dificuldade em se relacionar com a palavra (word). Durante o período em que Yolanda estava emocionalmente desequilibrada, ela também não conseguia pronunciar algumas palavras, e nem mesmo seus significados. Essa dificuldade em compreender o mundo se torna ainda pior quando ela desenvolve uma "alergia" em relação a algumas palavras. Nesse momento, nem mesmo seu nome estava seguro: "Her lips prickle and pucker. Oh no, she thinks, recognizing the first signs of her allergy - not my own name!" $(1992: 84){ }^{10}$ Yolanda estava mergulhada na depressão e perdendo seu equilíbrio emocional. Ela só consegue se restabelecer quando decide enfrentar a situação:

The words tumble out, making a sound like the rumble of distant thunder, taking shape, depth, and substance. Yo continues: 'Doc, rock, smock, luck,' so many words. There is no end to what can be said about the world (1992:85). ${ }^{11}$

No momento em que Yolanda sente que está na fronteira entre sanidade e insanidade, ela se apega às palavras para sobreviver. A literatura cumpre um papel importante nesse processo, principalmente por possibilitá-la compreender o que se passa com ela. Se durante sua infância, a poesia agia como refúgio, na fase adulta, Yolanda irá compreender que a escrita poderá ser o caminho do resgate de sua identidade. Através da literatura consegue entender suas perdas e seu sentimento de incompletude. Yolanda pode encontrar suas semelhanças na literatura identificando-se com outros autores, o que faz com que sinta mais segura. Tão logo, ela consegue dominar as palavras, ela consegue compreender a si mesma. É, portanto, nesse processo de mergulho nas profundezas de seu eu, que Yolanda emerge se apoiando na escrita.

Yolanda retorna ao passado, não somente geograficamente, mas também através das memórias. Nesta revisita, ela traz novamente suas experiências para resignificá-las no presente. Para Homi Bhabha:

O trabalho fronteiriço da cultura exige um encontro com o 'novo' que não seja parte do continuum de passado e presente. Ele cria uma idéia do novo como ato insurgente de tradução cultural. Essa arte não apenas retoma o passado como causa social ou precedente estético: ela renova o passado, refigurando-o como um 'entre-lugar' contingente, que inova e interrompe a atuação do presente. $\mathrm{O}$ 'passado-presente' torna-se parte da necessidade, e não da nostalgia, de viver (1998:27).

\footnotetext{
10 "Seus lábios formigam e se contraem. Ah não, ela pensa, reconhecendo os primeiros sinais de sua alergia - não meu próprio nome!" (minha tradução)

11 “'Doutor, rocha, avental, sorte', tantas palavras. Não há fim para o que pode ser dito em relação ao mundo." (minha tradução)
} 
Yolanda toma consciência da necessidade de interferir em seu presente, por isso ela revê seu passado. E diante da impossibilidade de mudar esse passado, a personagem percebe a necessidade da reorganização do presente. No momento em que entra em confusão mental, Yolanda sente que precisa retomar a escrita: "Maybe she will try writing again, nothing too ambitious, a fun poem in the limerick mode" (1992:82). Ela também compreende que essa retomada deve ser lenta. A passagem em que um pássaro preto enorme sai de sua boca parece simbolizar o momento em que ela se dá conta do valor da escrita em sua vida. Esse episódio funciona como um momento epifânico, principalmente por percebermos que a personagem se sente aliviada depois dessa externalização. Nesse sentido, a escrita para ela, não é somente um lugar de resistência, mas também uma questão de sobrevivência. O tex to será sua salvação.

No processo da escrita, Yolanda externaliza seu desconexo e fragmentado passado. Se por um lado, essa externalização dá a ela a possibilidade de visualizar diferentes experiências vividas, por outro, é através dessa percepção que ela identifica a necessidade de redefinir tais experiências e de se reconstituir como sujeito. Mais ainda, a partir da visão dos fragmentos desordenados no papel ela terá a possibilidade de restabelecer sua ordem. A articulação das palavras conjugadas com uma ordem cronológica dos eventos passados modela o texto que está sendo construído e ao mesmo tempo a leva a tomar uma nova direção em sua vida. O texto, de uma certa forma, pode abarcar tudo e ao mesmo tempo permitir a ela o rearranjo dos eventos passados. Portanto, a personagem irá encontrar sua referência no texto. O texto se torna seu porto seguro.

No exercício de reproduzir sua experiência, Yolanda reflete sobre suas atitudes e ao mesmo tempo assume o controle de sua própria vida. Tal conclusão pode também ser percebida na estrutura da narrativa, que assim como seu processo de construção da identidade se dá a partir da retrospectiva no tempo, a narrativa também se explica do presente em direção ao passado, ou seja, da fase adulta até a infância de Yolanda. Será no texto que Yolanda encontrará equilíbrio, tanto com as palavras como com o mundo. As outras vozes emergentes na narrativa são igualmente importantes, principalmente por complementarem e legitimarem a verdade de Yolanda. Ela dialoga com sua família e toma contato também com a experiência deles. Ao considerarmos os momentos traumáticos vividos por eles na República Dominicana, iremos perceber que estes não afligem somente ao presente de Yolanda, mas de toda a família. Embora fosse ainda criança ao ver o pai numa situação vulnerável em sua própria casa, Yolanda demonstra ter sido afetada por esse episódio. Será também por resgatar tais momentos passados que a personagem compreenderá que não poderia ter ofendido seu pai no presente ao fazer referências àquele período:

Probably, if she had thought a moment about it, she would not have done what she did next. She would have realized her father had lost brothers and friends to the dictator Trujillo. For the rest of his life, he would be haunted by blood in the streets and late night disappearances (1992:146). ${ }^{13}$

\footnotetext{
12 "Talvez ela tente escrever novamente, nada muito ambicioso, um poema divertido ao modo limerick." (minha tradução)

13 "Provavelmente, se ela tivesse pensado por um momento sequer sobre isso, não teria feito o que faria em seguida. Ela teria entendido que seu pai perdera irmãos e amigos para o ditador Trujillo. Para o resto de sua vida, ele seria assombrado pelo sangue nas ruas e os desaparecimentos nas madrugadas." (minha tradução)
} 
Se por um lado tal resgate traz sofrimentos à superfície, por outro será o fato de expor tais acontecimentos que fará com que consigam superá-los. No desenvolvimento da narrativa tomamos contato com o sofrimento e as difíceis experiências vividas por Yolanda reveladas por ela através da escrita. Nos parece ser o ato de registrar essas experiências que faz com que ela tenha uma nova compreensão dessa experiência vivida:

I went to school. I read books. You understand I am collapsing all time now that it fits in what's left in the hollow of my story? I began to write, the story of Pila, the story of my grandmother (1992:289). ${ }^{14}$

Yolanda traz à tona todos os seus fantasmas que a amedrontaram durante a infância e na jornada de volta aos seus ancestrais ela encontra explicação para seu presente e toma consciência de sua própria história.

Entretanto, não temos a idéia de que ela esteja pronta para o que vier em sua história de vida, ao contrário, temos a impressão de que ela está aprendendo a lidar com seus sentimentos. Em seu retorno à Republica Dominicana, Yolanda percebe que sua unidade não é mais possível principalmente por pertencer a duas diferentes culturas. Ela se sente ligada à cultura dominicana através de suas raízes familiares, mas está ainda ligada à cultura americana através da língua inglesa, da sua profissão e dos seus amigos. É contraditório, que Yolanda procure segurança na língua espanhola quando é em inglês que ela consegue se expressar. Talvez possamos afirmar que a condição dos imigrantes nos Estados Unidos tenha causado neles a perda de referência de sua própria língua. Aspectos como tempo e distância geográfica podem contribuir para esse comportamento e justificar essa perda.

A viagem a suas raízes parece resultar na consciência da impossibilidade em manter somente uma cultura. Em outras palavras, talvez essa reflexão sobre sua condição possa levá-la a compreender que ela estará sempre no que Silviano Santiago chama de "entre-lugar". E na tentativa de se acomodar nesse "entre-lugar", Yolanda assume sua incapacidade de se desvencilhar de ambas. Em outras palavras, a personagem revela seu duplo enquadramento. Para Juan Flores e George Yúdice:

Para vocalizar a fronteira, atravessa-la não é suficiente: precisamos nos situar nela, com um acesso imediato e simultâneo a ambos os lados" (1992:78).

Portanto, tal afirmação nos leva a concluir que Yolanda não permanecerá na República Dominicana, mas deverá retornar para os Estados Unidos com sua experiência renovada, ou seja, consciente da impossibilidade de se ajustar a uma única cultura.

Igualmente importante, será a escrita em sua vida:

I grew up, a curious woman, a woman of story ghosts and story devils, a woman prone to bad dreams and bad insomnia. There are still times I wake up at three o'clock in the morning and peer into the darkness. At that hour and in that loneliness, I hear her, a black furred thing lurking in the corners of my life,

\footnotetext{
14 "Eu fui para a escola. Eu li livros. Você compreende a razão do meu desequilíbrio que agora se encaixa no vazio da minha história? Comecei a escrever, a história da Pila, a história de minha avó." (minha tradução)
} 
her magenta mouth opening, wailing over some violation that lies at the center of my art (1992:290). ${ }^{15}$

Yolanda estabelece uma relação próxima entre sua vida e a arte. Em outras palavras, ela compreende seus medos e vulnerabilidades, mas encontra uma forma de superá-los através da escrita.

\title{
Bibliografia
}

ALVAREZ, Julia. How the García Girls Lost Their Accents. New York: Penguin Books, 1992.

BHABHA, Homi K. O Local da Cultura. Tradução de Myriam Ávila, Eliana Lourenço de Lima Reis, Gláucia Renate Gonçalves, Belo Horizonte: Ed. UFMG, 1998.

BELSEY, Catherine. "Constructing the Subject: Deconstructing the Text". In: Robyn R. Herndl and Diane Price (Eds). Feminisms: An Anthology of Literary Theory and Criticism. New Brunswick: Rutgers University Press, 1996. p. 593-609.

FLORES, Juan e George Yúdice. "Fronteiras vivas/Buscando América: as línguas da formação latina". In: Heloisa Buarque de Hollanda (Org.) Y Nosotras Latino americanas? Estudo sobre gênero e raça. São Paulo: Fundação Memorial da América Latina, 1992.

FOUCAULT, Michel. O que é um autor? Tradução de António Fernando Cascais e Edmundo Cordeiro, Veja: Passagens, 1992.

KRISTEVA, Julia. Estrangeiros para nós mesmos. Tradução de Maria Carlota Carvalho Gomes, Rio de Janeiro: Rocco, 1994.

MIRANDA, Wander Melo. Corpos Escritos: Graciliano Ramos e Silviano Santiago. São Paulo: Editora da Universidade de São Paulo; Belo Horizonte: Editora UFMG, 1992.

PIGLIA, Ricardo. Memória y tradicion. Anais do 2 Congresso Abralic. Belo Horizonte: UFMG, 1991. v. 1.

SAID, Edward W. Representations of the Intellectual: The 1993 Reith Lectures. London: Vintage, 1994.

\begin{abstract}
The aim of this work is to analyze the way in which Yolanda, a character in Julia Alvarez's novel How the García Girls Lost Their Accents, attempts at reconstructing her identity through her memories and how the process of writing contributes to this reconstruction. In her return to the past, the character rescues moments, which can explain her feelings of incompleteness. If, on the one hand, this search is very important in the sense that it will help her externalize her lacking and multiple I, on the other hand it is writing that will contribute to this reconstruction of the subject.
\end{abstract}

Key words: memories, identity, writing and subject.

\footnotetext{
15 "Eu cresci, uma mulher curiosa, uma mulher de história de fantasmas e demônios, uma mulher propensa a pesadelos e insônia. Há momentos ainda que acordo às três da manhã e observo a escuridão. Nesse momento, sozinha, eu a ouço, uma coisa peluda e preta nos cantos da minha vida, sua boca vermelha aberta, chorando alguma violação que reside no centro de minha arte.” (minha tradução)
} 
